\title{
Marketisation of Climate Change: Applying Chrematistics Framework to Warmth Rationing Issue in New Zealand
}

\author{
Djavlonbek Kadirov
}

\section{Introduction}

Climate change-induced air temperature irregularities brought the issue of thermal comfort to the forefront of societal discourse around the globe. In this chapter, I argue that a number of inadequacies in thermal comfort provisioning at a societal level are echoed in new societal practices and norms such as warmth rationing that emerged in New Zealand due to evolving marketisation processes in the energy supply market. To better elucidate the problem, I apply the chrematistics framework proposed by Kadirov Varey and Wolfenden (2016) that focuses on key market actors' manipulative practices that impact the market system's structure, design and operations. Marketisation in itself appears to be a neutral process, except when it becomes coupled with a chrematistics motive, i.e. unconstrained wealth acquisition. The negative effect of chrematistics is reflected in wealth acquisition turning into a guiding value over societal well-being, the process which is underscored by the industry's growing capability to manipulate citizens' access to warmth. This chapter will explore how marketisation is linked to the chrematistics drive that diverts society away from the goal of provisioning affordable, reliable and sustainable energy.

\section{Thermal Comfort Provisioning}

As the threat of significant climate change is looming, many people are pondering about its potential effects by asking questions like "how hot is too hot?" or "how cold is too cold?" (BBC 2013). Climate anomalies such as heat waves, cold snaps, flash floods, storms and hurricanes are expected to intensify. In such circumstances,

D. Kadirov (凶)

Victoria University of Wellington, Wellington, New Zealand

e-mail: djavlonbek.kadirov@vuw.ac.nz 
the problem of thermal comfort and its maintenance may become one of the pressing issues of the humanity in future. The World Health Organisation (WHO) set the boundaries of indoor thermal comfort between 18 and $24^{\circ} \mathrm{C}$. Sustained comfortable air temperature is one of the basics of life just like food or water. Maintaining thermal comfort requires human effort, and by implication gives rise to unavoidable societal cost, specifically, when outdoor temperatures fluctuate beyond the WHO limits. If in some parts of the Northern hemisphere people suffer from extremely hot weather in the summer, just about the same time, some parts of the Southern hemisphere struggle against cold weather. Specifically, in New Zealand, the thermal comfort issue turns into a problem of maintaining comfortable indoor warmth. Here, in the domain of warmth provisioning, one would be able to note a clash of two different perspectives: societal versus market (Kadirov and Varey 2011, 2013). The societal perspective emphasises equal access to warmth for all, while the market perspective stresses warmth distribution based on affordability. In other words, the market perspective supports the claim that warmth should be supplied to only those who can afford to pay the price. The plight of vulnerable population (e.g. children, elderly and large families) would be underemphasised from this point of view.

What can be observed currently is that the clash of two rival perspectives is being played out in the energy sector of New Zealand. Marketisation, observed via gradual deregulation of the industry, led to the situation that energy prices steadily increased (Bertram 2015). No doubt that the industry benefited from these changes reporting healthy revenues, while some players in the market artificially inflated their operational costs to be able to claim tax exemptions and increased mark-ups. However, about the same time, a treacherous institutional tendency developed among the population. An increased number of people started rationing warmth for themselves and their family members. Some people referred to this tendency as simply "going cold" (Stuff 2018a). The 2018 nationwide survey by Perceptive Research covering 1356 households indicated that $67 \%$ of New Zealanders are very concerned about the cost of heating and that $53 \%$ of them often choose to go without heating just because of high cost. This tendency is very high $(69 \%)$ in Otago, which tends to be the coldest region in winter. As "going cold" turned into a norm affecting people from all walks of life, the negative impact of this norm appears to affect the most vulnerable parts of the population. Research shows that in New Zealand, inadequate indoor warmth translates into excess winter mortality (Davie et al. 2007; Hales et al. 2012). In addition, high prices led to experimentation with alternative means of heating (e.g. stove and barbeque) causing fire safety issues (The Spinoff 2017).

It must be noted that warmth rationing is a complex problem. Apart from energy prices, many other different factors influence its dynamics. Such factors may include historical norms, building standards, availability of various heating options, technology, government subsidies and so on. For example, until recently many New Zealanders felt that central heating is a waste of money or heating a home is like burning money (BBC 2011; Howden-Chapman et al. 2009). Before the recent changes introduced by the government for healthy homes, old house building standards encouraged inadequate energy efficiency (Howden-Chapman et al. 2009). Also, government 
subsidies such as the Winter Energy Payment scheme focus on helping the most vulnerable layers of the population. Nevertheless, the main driving force appears to be the dynamics of the energy market in the country. For most people, warmth rationing is a matter of affordability and cost rather than behavioural preference. Next, we outline the chrematistics framework that is applied to shed light on the problem.

\section{Chrematistics Framework}

The chrematistics framework focuses on manipulative influence of market actors on ways through which markets operate. Since there are different market actors wielding different levels of power in different positions within the market system (Kadirov 2018), some actors may find themselves as more advantaged in terms of shaping the system to their liking. Specifically, bigger corporations can influence the structure and processes of a market system through focused lobbying, backchannel deals, personal relationships and providing support to people in key positions. The notion of "chrematistics" is an ancient term that dates back to Aristotle's thinking. He defined chrematistics as an art of wealth multiplication. Wealth accumulation is not necessarily a negative process, however, it has been criticised by virtue philosophers and ethics thinkers as a starting point of a greater problem: money making for the sake of money making. Specifically, chrematistics turns into a formidable force when the provisioning of life necessities is transformed into a money-generating system at the expense of societal welfare. Kadirov et al. (2016) reformulated the concept of chrematistics as a participative process through which powerful market actors engage in market system design and manipulate its processes in order to maximise their own pecuniary benefits. Money-making is a positive process if it serves the provisioning goals of society. However, in the energy market system, in New Zealand, chrematistics turned into the manipulation of citizens' access to warmth at the expense of societal well-being. Kadirov et al. (2016) show that the chrematistics process involves the following steps: (a) identification of a market system; (b) examination of manifestations of chrematistics; (c) evaluation of the opportunity costs of policy choices and (d) analysis of misleading societal communication.

\section{Applying Chrematistics Framework to Warmth Rationing Dynamics}

\section{Market System Identification}

A market system can be seen as a collection of different market actors pursuing different goals. The energy generated by the industry is consumed by three groups: industrial actors (e.g. the aluminium smelter), commercial customers and individual 
households. Warmth rationing relates to individual household practices, which represent only about $30 \%$ of total energy consumption in New Zealand. However, despite its small proportion, due to the number of actors involved (i.e. all households), this portion of consumption significantly impacts societal well-being. Consumers are closely related to other societal stakeholders such as researchers, investigators, commentators and media. The other group of stakeholders includes associations such as Consumer NZ, Business NZ Energy Council, Electricity Networks Association, Electricity Retailers' Association NZ and Major Electricity Users' Group. These groups are augmented by government actors such as Commerce Commission, Ministry of Consumer Affairs, Electricity and Gas Complaints Commission, Energy Efficiency and Conservation Authority, the Ministry for the Environment and the Ministry of Business, Innovation and Employment. The government has also created Electricity Authority that independently regulates the market. On the electricity supply side, the following actors are part of the system: (a) energy retailers (about 25 small and five big companies which sell energy to final consumers; (b) local distribution networks which are represented by regional enterprises that operate most local low voltage lines; (c) the national transmission network operated by a state-owned company Transpower that operates high-voltage lines; and (d) power-generating companies including the Big Five: Genesis Energy, Contact Energy, Meridian Energy, Mercury Energy and Trust Power). These five companies control over $90 \%$ of energy supply in this market system. In a well operating, effective and sustainable market system, energy provisioning is expected to solve the "energy trilemma", that is energy supplied must be (1) accessible to all societal actors; (2) continuous without major interruptions and (3) minimally damaging to the natural environment.

Marketisation encapsulated in deepening deregulation of the market was at first very promising. Starting from 1999, the deregulative reforms pursued the goal of forming classic perfect competition in the market. However, two decades later, the end result appears to be far from what was intended at that time. Currently, this market system represents a hodgepodge of regulative, normative and market structures with some remotely resembling characteristics of competitive markets. Yet, government agencies argue that some competition exists. For instance, Electricity Authority NZ claims wholesale sales and retail sales happen on a competitive basis. In the wholesale domain, a spot market operates where customers competitively bid for energy, while in the retail domain, consumers can easily switch between retailers. Nevertheless, the whole market system appears to be biased towards commercial users at the expense of residential customers and individual households. The 2016 review by International Energy Agency (IEA) shows that recent increases in energy prices for residential customers New Zealand were so significant that it exceeded the IEA average. Since it was hoped that deregulation would result in a price decrease in a long-term, this was not good news. The Ministry of Energy and Resources and the Ministry of Business, Innovation, and Employment were on the move of examining electricity prices. The minister Megan Woods commented: "residential electricity prices have risen by around $50 \%$ since 2000 but the price for business remained flat. We want to find out why that is". New Zealand's public expected radical changes, however, after 
the review process, the ministry advised that nothing indicates that energy prices were not fair or equitable. However, this did not change the fact that the system was not performing as expected.

\section{Manifesting Signs of Chrematistics}

Chrematistics can be recognised by its symptoms (Kadirov et al. 2016). An important manifestation of chrematistics is related to the priorities empathised in system design. As it has been suggested, the energy provisioning system must be built to deliver affordable, sustainable and reliable energy to all customers. This must be the main target set for the whole system, while individual actors within the system should be allowed to pursue self-interest without jeopardising the overarching goal. A problem occurs when these two types of goals (macro versus micro) are confused. A case in point is Contact Energy Ltd that acted so unabashedly to the detriment of broader stakeholder groups and the whole system that it was granted the 2004 Roger Award for being the worst transitional corporation (Newberry and Rosenberg 2005). A single company can be forgiven for the only-for-profit motivation; however, the success for the whole system is not to be measured by how much money is accumulated in the businesses' accounts or by the extent of dividends paid to shareholders. The market system is not a machine that works to turn societal grievance (e.g. warmth rationing) into cash. Moreover, it should not be turned into a domain of lucrative investment portfolios that allow the rich to get richer. Hijacking the whole system by turning it into a safe haven for investors defeats the whole purpose of system design.

Another manifestation of chrematistics appears to be a trend of "corporatisation". Corporatisation involves the assumption that private capital and privatisation are the only best options for the design of the system. It rests on another assumption that the whole system must be put to work for shareholders, who would somehow direct businesses to benefit consumers in general. Deregulation started with the 1986 Commerce Act which helped to replace public enterprises with private ones (Newberry and Rosenberg 2005). The deregulation was expected to engender increased competition, however, in a oligopolistic market where there were only few energy suppliers fair competition was perhaps the last thing in the mind of these producers. A report from Wolak (2009) indicated that electricity producers in New Zealand wielded excessive power to be able to manipulate the market. The report estimated that over the seven years that were studied society bore about NZD 4.3 billion unnecessary cost in the form of customer overcharge. Dr Geoff Bertram (Victoria University of Wellington) estimated that in the last thirty years, different manipulations allowed the industry to extract unfair earnings totalling NZD 14 billion. The market system, under deregulation, transformed into an effective machine of cash surplus creation (Beder 2013). At the same time, society members suffered from increased rates of winter mortality, child sickness, heating problems, emergencies such as fire, and the last but not the least, poverty. The government failed to protect its citizens, as it 
appeared that major investors were based overseas. For example, overseas investors own $62 \%$ of Contact Energy's shares (Newberry and Rosenberg 2005).

It is to be noted that marketisation tends to turn society members into consumers. However, not all can qualify since consumers are those people who can afford the market offering. If "consumer is the king", then how should one treat the "nonconsumer"? As deregulation and privatisation increased, the ranks of non-consumers expanded. It can be seen in increasing rates of network disconnections (RadioNZ 2018). The irony is that in free markets, one can choose to not choose a market offering. When it comes to thermal comfort, not many can opt out of this basic human need. Hence, free market is impossible in this context (Easton 1995). Although Electricity Authority blindly believes that free market is still possible, in reality the electricity market appears to be the sellers' market, since demand for energy is inelastic. This allows electricity providers to manipulate the market. Wolak (2009) argued that electricity is not a typical commodity: it does not represent a marketable product. Rather, its producer is in good position to wield excessive power. In a retail domain, consumers are allowed to switch suppliers. However, such a freedom is miniscule since all retailers provide the same commodity with almost similar prices.

\section{Opportunity Cost of Policy Choices}

Every decision in system design implies an opportunity cost. By making specific decisions, public policy makers forgo other possibilities (Kadirov et al. 2016). By pursuing privatisation, the government rejected some propositions supporting an option of a single wholesale purchaser of all electricity. This option would effectively eliminate the manipulative influences of electricity generating companies and seal off the retailing domain from negative impacts. Moreover, Kapp's (2015) "social maxima/minima" notion can be put into use by offering a standard nationwide contract with fixed prices. This would allow retailers to sell a simplified standard package as well as offering differentiated or customised services built on top of this package. The standardised package would guarantee access to energy for all, while customised services would serve customers requiring specialised services. Moreover, the supply of electricity appears to be an engineering problem rather than a marketing problem. Hence, a carefully designed system resembling a centrally planned electricity supply network that focuses on innovation may successfully replace the current hodgepodge market-imitating system. In addition, other opportunities may as well need further exploration in future. Distributed electricity generation or small-scale sustainable generation options are increasingly becoming viable. The experience of other countries (e.g. Germany) needs to be carefully examined in this respect (Hanson 2017). The system of Solar Commons (www.solarcommons.org) is another possibility. This system considers providing solar systems to households to generate savings which are passed on to low-income consumers. This kind of project is currently operating in Tucson, Arizona (Hanson 2017). 


\section{Misleading Societal Discourse}

Chrematistics is often accompanied with misleading logical arguments that distract from the essence of the problem (Kadirov et al. 2016). One of such misleading discourse is the sustainability target set for the industry in terms of the share of renewable electricity generation. It is expected that New Zealand would reach the $90 \%$ mark for renewable energy by 2025. Most stakeholders emphasise this target as though it is the single most important measure that would solve all energy generation problems. However, how relevant is this target in the context of the problem of warmth rationing? Would making system more "clean and green" satisfy the societal need for affordable energy? Sustainability is not to be underemphasised; however, it should not come at the expense of societal degradation (Kadirov 2011). Another misleading narrative concerns the "death cycle" related to households choosing to install solar panels. Instead of encouraging the move towards renewable energy generation, these households are being framed as a "burden" to the existing networks. Unfortunately, government officials in some cases reinforce such narratives. The minister of Energy and Resources Megan Woods commented: "the government is watching to make sure low-income consumers don't end up facing higher electricity costs caused by wealthier people installing solar power units" (Stuff 2018b, np). The anti-solar rhetoric turned into practice in some cases where some local network operators introduced a so-called solar charge. Such rhetoric, supported through a string of media publications supported by the industry, can be considered an attempt to avoid widely accepted practices of "net metering" and feed-in tariffs which ensure crediting the customer's account for the amount of energy they produce. Furthermore, another distracting discourse is a debate that focuses on privatisation versus nationalisation (Beder 2013). Instead of focusing on real problems such as narrow-minded chrematistics, which would result in the same outcome in both socialist and capitalist systems, commentators warn about the perils of socialist systems. Some of the commentators go even further juxtaposing marketisation to communitarian feelings. In fact, it appears that chrematistics is the common eigen value of any system. Irrespective of market or communal initiatives, chrematistics leads to corruption where specific groups position themselves in a way that they are able to take advantage of other market actors.

\section{Conclusion and Implications}

In its current form, the energy market system in New Zealand fails to satisfy the need for accessible, sustainable and constant energy that would address problems related to warmth rationing. At the same time, applying the marketisation perspective, some stakeholders think that New Zealand energy markets represent a very successful industry. This judgement is based on the industry's supposed efficiency and its capacity for profit-generation. It is somewhat true that the system appears to 
be market-efficient: it turns human suffering into a steady stream (electronic record) of commonly accepted currency valued by investors. However, the system is not wellbeing-efficient: it ignores warmth rationing related issues, while failing to accomplish its macro-societal role. Hence, the author maintains that the chrematistics turn supported by marketisation processes is a path towards exploitation. This is the exploitation of a unique kind that which is afforded by the logic of neo-liberal markets (Bertram 2015). Perhaps, it is an opportune time to initiate a complex re-design of the whole system so that the goals of societal provisioning for warmth are considered a top priority. The chrematistics turn transforms "warmth" into a product that is sold in the "market" with a view of generating maximum revenue. In contrast, warmth should be seen as the basic human right as well as a common resource. It must be generated, exchanged, shared and consumed in a more community-friendly way (Martinez 2017). Warmth is a resource that is closely related to human dignity (Jagadale et al. 2018).

A process of marketisation may lead to negative societal outcomes; however, such outcomes can be avoided if a number of issues are satisfactorily resolved. From the government's perspective, a straightforward approach appears to be the initiation of marginal programmes to tackle visible consequences of marketisation while avoiding major structural reforms of the energy sector. The recently initiated government's programmes such as Winter Energy Payment (initiated from May 2019; grants eligible beneficiaries, e.g. the receivers of New Zealand superannuation and veterans'pension, unemployed, sole parents, young parents, financial support during winter to help with house heating costs), Warmer Kiwi Homes (low-income households can access grants covering up to $67 \%$ of the cost of efficient warmth solutions such as heat pump or house insulation), and Voluntary Targeted Rates (local councils offer low interest-rate financing which is paid off as a part of the rates over a long-time period) are focused on mitigating severe impacts of warmth marketisation on the vulnerable. However, transformative reforms of the energy generation sector may be needed. A well-regulated distributed renewable energy (e.g. solar, wind, hydro) buyback scheme can be an option. Despite frequent public outcry, consumergenerator complaints and media pressure, New Zealand Electricity Authority has so far resisted the introduction of compulsory solar buyback schemes (NZ Electricity Authority 2015) arguing that the market is a free competitive market where the retailers are "free" to decide whether they should pay fair (if any) price for excess electricity generated by distributed networks. In fact, Electricity Authority decided not to interfere when some network operators (e.g. Unison) started charging solarpower-generating customers an extra fee to cover, as they claim, these customers' "fair share" of grid maintenance costs (Solar City 2019). Moreover, some voiced the wrong assumption that solar power would "cannibalise" wind- and hydro-based energy generation networks.

To mitigate the impact of marketisation, Bertram (2015) offers two solutions: (a) the government must assume the role of the protector of residential energy consumers and distributed generators and (b) the use of the commons such as water, wind and solar energy must be regulated to the benefit of society. In general, a transformative solution is needed. The author proposes the creation of a public energy generating 
network (which could unify all other distribute networks) or a single energy buyer that sets a "social minima" price per a unit of energy commodity. Given the recent advances in energy technologies, artificial intelligence and digital networks, energy provisioning can be treated as a technical problem rather than that of an efficient market. This approach would be akin to setting a liveable minimum wage rate. The basic no-frills option supplied through well-designed networks would set an anchor price for all other retailers, while at the same leaving enough room for powerful industry players to further innovation and creativity in tailoring their products to idiosyncratic customer needs and becoming constructive participants in the total system of provisioning adequate warmth that represents one of the fundamental human rights.

\section{References}

BBC. 2013. Can the body cope with 50C? https://www.bbc.com/news/world-asia-0956421.

BBC. 2011. How warm is your home? www.bbc.com/news/magazine-12606943.

Beder, Sharon. 2013. The Real Cause of Electricity Price Rises. Australian Options 72 (Autumn): $14-16$.

Bertram, Geoff. 2015. Neoliberalism and Energy Poverty: Why corporatisation, deregulation and privatisation doubled the cost of electricity for New Zealand households. Victoria University of Wellington. http://www.geoffbertram.com/publications/?no_cache=1.

Davie, Gabrielle S., Michael G. Baker, Simon Hales, and John B. Carlin. 2007. Trends And Determinants of Excess Winter Mortality in New Zealand: 1980 to 2000. BMC Public Health 7 (1): 263-272.

Easton, Brian. 1995. Competitive Electricity: Whatever the Equation, Power Prices Will Rise. Listener, 56 (July).

Hales, Simon, Tony Blakely, Rachel H. Foster, Michael G. Baker, and Philippa Howden-Chapman. 2012. Seasonal Patterns of Mortality in Relation to Social Factors. Journal of Epidemiology and Community Health 66 (4): 379-384.

Hanson, Francesco. 2017. The Sun Shines for Everyone: Creating Community Solar Business Models that Include Culturally and Geographically Diverse Low-Income Americans. Lindmark Fellowship in Ethics, 3, https://digitalcommons.csbsju.edu.

Howden-Chapman, Philippa, Helen Viggers, Ralph Chapman, Des O'Dea, Sarah Free, and Kimberley O'Sullivan. 2009. Warm Homes: Drivers of the Demand for Heating in the Residential Sector in New Zealand. Energy Policy 37 (9): 3387-3399.

Jagadale, Sujit R., Kadirov Djavlonbek, and Chakraborty Debojyoti. 2018. Tackling the Subaltern Quandary: Marketing Systems of Dignity. Journal of Macromarketing 38 (1): 91-111.

Kadirov, Djavlonbek. 2011. Macro-Systems Role of Marketing: Do We Trade Environment for Welfare? Journal of Macromarketing 31 (4): 359-375.

Kadirov, Djavlonbek. 2018. Towards a Theory of Marketing Systems as the Public Good. Journal of Macromarketing 38 (3): 278-297.

Kadirov, Djavlonbek, and Richard J. Varey. 2011. Symbolism in Marketing Systems. Journal of Macromarketing 31 (2): 160-171.

Kadirov, Djavlonbek, and Richard J. Varey. 2013. Social Systems, Social Provisioning, and Marketing's Purpose. Social Business 3 (3): 185-199.

Kadirov, Djavlonbek, Richard J. Varey, and Sally Wolfenden. 2016. Investigating Chrematistics in Marketing Systems: A Research Framework. Journal of Macromarketing 36 (1): 54-67.

Kapp, K.William. 2015. The Heterodox Theory of Social Costs. London: Routledge. 
Martinez, Cecilia. 2017. From Commodification to the Commons: Charting the Pathway for Energy Democracy. In Energy Democracy, ed. Denise Fairchild and Al Weinrub, 21-36. Washington, DC: Island Press.

Newberry, Sue and Bill Rosenberg. 2005. Electricity Reforms and Contact Energy Ltd. www. converge.org.nz/watchdog/08/06.htm.

NZ Electricity Authority. 2015. Response to Solar Electricity Petition. https://www.ea.govt.nz/ about-us/what-we-do/our-history/archive/dev-archive/work-programmes/market-wholesaleand-retail-work/investigating-barriers-facing-small-scale-distributed-generationregulatedarragnements-for-small-scale-distributed-generation/correspondence/response-to-solarelectricity-petition/.

Radio NZ. 2018. Surge in Electricity Disconnections over Unpaid Bills. www.radionz.co.nz/news/ national/359094/surge-in-electricity-disconnections-over-unpaid-bills.

Solar City. 2019. We're calling for Unison's solar tax to be scrapped. https://www.solarcity.co.nz/ blog/new-zealand-solar-news/were-calling-for-unisons-solar-tax-to-be-scrapped.

Stuff. 2018a. Being Cold and Rationing Heating is Now 'Normal' in New Zealand. www.stuff.co.nz/ business/money/104100512/being-cold-and-rationing-heating-is-now-normal-in-new-zealand.

Stuff. 2018b. Way To Be Cleared For Big Electricity Players to Prey on LowIncome Households. www.stuff.co.nz/national/politics/opinion/102708888/way-to-be-clearedfor-big-electricity-players-to-prey-on-lowincome-households.

The Spinoff. 2017. 'It Wasn't Supposed To Be Like This': Starting Life From Scratch in Industrial West Auckland. https://thespinoff.co.nz/auckland/22-03-2017/it-wasnt-supposed-tobe-like-this-starting-life-from-scratch-in-industrial-west-auckland/.

Wolak, Frank A. 2009. An Assessment of the Performance of the New Zealand Wholesale Electricity Market. Wellington, New Zealand: Report for the New Zealand Commerce Commission.

Djavlonbek Kadirov (Ph.D., University of Waikato) is a senior lecturer in marketing at the School of Marketing and International Business, Victoria University of Wellington, New Zealand. Djavlonbek's research interests include marketing systems theory, symbolism in marketing systems, sustainable marketing, and marketing morality. His research has appeared in journals such as Journal of Macromarketing, Journal of Marketing Management, Journal of Business Research, Journal of Brand Management, Consumption Markets and Culture, and Journal of Customer Behaviour. 